\title{
Experiments on the spelling-to-sound regularity effect in word recognition
}

\author{
KEITH E. STANOVICH \\ Oakland University, Rochester, Michigan 48063 \\ and \\ DAVID W. BAUER \\ University of California, San Diego, California 92037
}

\begin{abstract}
Subjects responded faster to words with regular spelling-to-sound correspondences than to words with irregular correspondences in both a naming task and a lexical decision task. The locus of the small, but significant, regularity effect was investigated in further experiments. When subjects were forced to respond faster than usual, via a response-deadline technique, no regularity effect was apparent in either their reaction times or error rates. In another experiment, no Regularity by Stimulus Quality interaction was obtained. It was concluded that the phonological recoding implied by the existence of the regularity effect takes place subsequent to lexical access.
\end{abstract}

The question of whether phonological recoding is an obligatory process in reading goes back at least to the time of Huey $(1908 / 1968)$. Modern investigators have tended to reduce the problem to whether or not phonological recoding is involved in word recognition, although it should be noted that somewhat different questions are at issue when the problem is so reduced (see Kleiman, 1975). Although adherents to the obligatory phonological recoding hypothesis (e.g., Gough \& Cosky, 1977; Rubenstein, Lewis, \& Rubenstein, 1971) and the competing visual access hypothesis (e.g., Green \& Shallice, 1976; Smith, 1971) still argue persuasively, several investigators have opted for the view that visual, phonological, and semantic processing go on in parallel (e.g., Meyer, Schvaneveldt, \& Ruddy, 1974; Shulman \& Davison, 1977). Another conceptualization is a dual-coding notion, whereby the internal lexicon is typically accessed via one type of representation (i.e., the visual), but under certain circumstances access can occur via another type (i.e., a phonological code). Kleiman (1975) presents such a model.

In recent years several different experimental techniques have been applied to the study of phonological recoding in word recognition. These include lexical decision tasks (Meyer et al., 1974), semantic classification tasks (Green \& Shallice, 1976), dual-task interference paradigms (Kleiman, 1975), naming tasks (Theios \& Muise, 1977), and studies of aphasic individuals (Saffran \& Marin, 1977). However, one of

The research was partially supported by the National Science Foundation Grant BNS76-82815. Requests for reprints should be sent to Keith E. Stanovich, Department of Psychology, Oakland University, Rochester, Michigan 48063. the most compelling demonstrations of the use of phonological recoding in word recognition comes from one of the simplest of paradigms. Baron and Strawson (1976) had subjects read aloud lists of 10 words as fast as possible. The lists varied in the degree to which their component words followed spellingto-sound correspondence rules. Lists composed of regular words (words following spelling-to-sound correspondence rules) were read faster than lists composed of irregular words (words not following such rules) when factors such as word frequency and word length were controlled. The data reported by Baron and Strawson (1976) suggest that the effect is sizable, approximately $165 \mathrm{msec} /$ word. However, there are several problems with their procedure of having subjects read through lists of words. The problems all revolve around the fact that the time to read a given list is composed of the times for several component mental operations in addition to recognition time. For example, articulation latency, the time to execute the motor commands to name a word, is a component of the total time. It may be that irregular words simply take more time to articulate than regular words. However, no control for articulation latency is provided in the Baron and Strawson (1976) study. Additionally, the production latencies (the time to retrieve and initiate the motor commands for vocalizing a word) of irregular and regular words may differ. In short, the rather impressive regular-irregular difference displayed in the Baron and Strawson (1976) study may not be due to processes involved in recognition at all, but instead might simply be due to differences in the articulatory characteristics of the words.

Gough and Cosky (1977) provide evidence that articulation latency may have been a factor in the large 
regular-irregular difference reported by Baron and Strawson (1976). Gough and Cosky (1977) had subjects name single words and measured the time to initiate the response. Thus, differential articulation latencies were not implicated in the response times. Using regular and irregular words that were fairly closely matched on number of letters, number of syllables, form class, initial letter, initial phoneme, and frequency, Gough and Cosky (1977) found that reaction time to irregular words exceeded that to regular words by $27 \mathrm{msec}$. While this difference was statistically significant, it suggests a regularity effect considerably smaller than the $165 \mathrm{msec}$ of Baron and Strawson (1976). Furthermore, Gough and Cosky (1977) reported no comparison of the production latencies of their sets of words. It is possible that their regular and irregular words differed in mean production latency and that response initiation processes subsequent to recognition were responsible for the 27-msec difference. Experiment 1 investigates this possibility. Subjects named regular and irregular words in an experimental situation like that of Gough and Cosky (1977). In addition, production latencies were obtained for the two sets of words. Finally, two simple measures of reading ability were administered in order to investigate whether performance in this laboratory task is related to actual reading proficiency.

\section{EXPERIMENT 1}

\section{Method}

Subjects. The subjects were 16 undergraduate college students who were recruited through an introductory psychology subject pool for participation in the study.

Stimuli and Apparatus. A PDP-1 computer controlled the presentation of stimuli while recording responses and response latencies. A voice key was attached to the computer so that the reaction time could be measured. The stimuli were presented on a Hewlett Packard 1311A display device and subjects sat approximately $70 \mathrm{~cm}$ from the display.

The stimuli were 50 words with regular spelling-to-sound correspondences and 50 words with irregular spelling-to-sound correspondences. The irregular words were all either exceptions or minor correspondences as defined by Venezky (1970). The majority of both types of words were taken from Table 1 of the study by Baron and Strawson (1976). The two sets of words were equated on word frequency (mean regular frequency $=64.5, \mathrm{SD}=106 ;$ mean irregular frequency $=64.6$, $\mathrm{SD}=84$; according to the Kucera \& Francis, 1967, count) and word length (each set containing 1 three-letter word, 20 fourletter words, 20 five-letter words, 8 six-letter words, and 1 seven-letter word). Whenever possible, a regular word was chosen so that there was a close graphemic correspondence between it and an irregular word, thus insuring that the two types did not differ in the sequential constraints of their component letters. The words were composed of uppercase letters. Four-letter words subtended a horizontal visual angle of approximately $3.27 \mathrm{deg}$.

Procedure. Subjects were seated in front of the display and told that they would be seeing a series of words on the screen, one at a time. They were instructed to name each word as quickly and as accurately as possible. Following the instructions, the 100 words were presented in a sequence generated by a pseudorandom computer algorithm, subject only to the constraint that each stimulus appear exactly once. Subsequent to this block of trials, the production latencies were determined. Subjects were told that they would be seeing the same 100 words, but that they were not to respond until a plus sign appeared on the screen. One hundred trials were then completed in which a word was presented for $1.5 \mathrm{sec}$, followed by a blank interval that varied randomly between 1.4 and $3 \mathrm{sec}$. A plus sign then appeared, which was the signal for the subject to respond.

Following the 100 production-latency trials, subjects were asked to read silently a 600 -word passage taken from a popular magazine. They were instructed to read the passage for comprehension. The experimenter measured the reading time to the nearest $.1 \mathrm{sec}$ using a hand-held stopwatch. After reading the passage, the subject was asked several questions of content, to insure that he had been reading for meaning. Finally, the reading subtest (Level In) of the Wide Range Achievement Test (WRAT) (Guidance Associates of Delaware, Wilmington, Delaware) was administered to each subject. The test is one in which the subject names a series of words of increasing difficulty, his score being simply the number of words correctly named.

\section{Results and Discussion}

The mean reaction time to the regular words was $552 \mathrm{msec}(\mathrm{SE}=11 \mathrm{msec})$ and the mean reaction time to the irregular words was $570 \mathrm{msec}$ ( $\mathrm{SE}=13 \mathrm{msec}$ ). This 18-msec difference was significant at the .01 level $[t(15)=2.96]$. The mean production latency for the regular words was $417 \mathrm{msec}(\mathrm{SE}=15)$ and the mean production latency for the irregular words was $420 \mathrm{msec}$ $(\mathrm{SE}=15)$. This 3-msec difference did not approach significance. Words were treated as a fixed effect in these analyses, since fulfilling the constraints of equality of word length and frequency across the two word types leads to a sample of words that is clearly not randomly selected (Keppel, 1976; Wike \& Church, 1976). The regularity effect displayed in this experiment was small, although statistically significant, and was of a size similar to that reported by Gough and Cosky (1977) (i.e., an order of magnitude smaller than that suggested in the Baron \& Strawson, 1976, data). The results reported here are not subject to the alternative explanation that the regularity effect was due to production-latency differences in the two types of words, since these times did not differ. It appears that spelling-to-sound correspondence does affect the time to name a word, but compared to the other operations involved in the recognition process, the regularity effect is rather small.

A suggestive pattern emerged when the two measures of reading ability were correlated with a number of dependent variables taken from the naming task. First of all, scores on the reading subtest of the WRAT correlated significantly with silent reading time (Pearson $\mathrm{r}=-.55, \mathrm{p}<.025)$. It is interesting that silent reading time (a speed measure) would correlate so highly with the WRAT, which involves only the ability to correctly pronounce words. Furthermore, this pattern of the WRAT (a nonspeed measure) correlating with speed measures extended to correlations involving measures 
from the naming task. Correlations significant at the .01 level were obtained between the WRAT and both mean time to name regular words $(\mathrm{r}=-.58)$ and mean time to name irregular words $(r=-.62)$. The correlation between silent reading time and mean regular reaction time was .23 (n.s.) and the correlation between silent reading time and irregular reaction time was .44 $(p<.05)$. Finally, for each subject the mean time to name regular words was subtracted from the mean time to name irregular words. This difference score displayed a significant correlation with silent reading time $(\mathrm{r}=.53$, $\mathrm{p}<.025$ ), although its correlation with WRAT scores did not reach significance $(r=-.25)$. However, the direction of both correlations indicates that better readers showed a smaller regularity effect. These correlational results appear to suggest that better readers rely less on phonological recoding, apparently relying more on direct visual access. However, any conclusions based on these rather crude measures of reading ability must certainly be tentative.

\section{EXPERIMENT 2}

It can always be argued that extrapolating the results from word-naming tasks to the actual reading situation is not justified since a word can be named without lexical access (e.g., by processes like those used to name nonwords). Several investigators have used lexical decision tasks as alternatives to naming. It is thus of interest to see whether the regularity effect observed in Experiment 1 and by Gough and Cosky (1977) will obtain in a lexical decision task. A comparison of the two tasks with respect to this variable seems particularly crucial given that they have produced completely different patterns of results in experiments involving other factors relevant to word recognition. For example, in naming tasks, reaction time increases monotonically with word length, whereas word length has no effect on lexical decision times (Cosky, 1976; Frederiksen \& Kroll, 1976; Richardson, 1976). On the other hand, lexical decision tasks display a much larger wordfrequency effect than do naming tasks (Frederiksen \& Kroll, 1976; Richardson, 1976; Scarborough, Cortese, \& Scarborough, 1977; Theios \& Muise, 1977). It is thus not at all clear that the two tasks will produce results that are convergent as regards the effect of spellingto-sound correspondence on word recognition. In Experiment 2, subjects responded to the stimulus words of Experiment 1 in the context of a lexical decision task.

\footnotetext{
Method

The subjects were 16 undergraduate college students who were recruited through an introductory psychology subject pool for participation in the study. None had participated in Experiment 1. The apparatus was the same as in Experiment 1, except that the subject responded by pressing a key on a microswitch keyboard. He was instructed to push the key under his left index finger if the letter string was a word and to push
}

the key under his right index finger if the stimulus was a nonword. Each subject completed a block of 150 trials consisting of the 50 regular and 50 irregular words from Experiment 1, plus 50 pronounceable nonwords that were composed by combining two- and three-letter strings from the 100 words. Subjects were told to respond as quickly and accurately as possible. The WRAT and the passage to be read silently were administered as in Experiment 1.

\section{Results and Discussion}

The mean reaction time to the regular words was $623 \mathrm{msec}$ ( $\mathrm{SE}=25 \mathrm{msec}$ ) and the mean reaction time to the irregular words was $645 \mathrm{msec}(\mathrm{SE}=25 \mathrm{msec}$ ). This 22-msec difference was significant at the .025 level $[t(15)=2.51]$. The mean percentage correct on regular word trials was $97.4 \%$ and the mean percentage correct on irregular word trials was $94.5 \%[\mathrm{t}(15)=2.40$, $\mathrm{p}<.025]$. These results indicate that there is a small but significant effect of word regularity in a lexical decision task. That the magnitude of the effect in the lexical decision task $(22 \mathrm{msec})$ was similar to that obtained in the naming task of Experiment 1 (18 msec) is particularly impressive, given that the two tasks have produced markedly divergent results in other word-recognition experiments (see Frederiksen \& Kroll, 1976).

As in Experiment 1, the two measures of reading ability correlated with each other $(r=-.56, p<.025)$. In addition, WRAT scores correlated with reaction time to nonwords $(r=-.59, \mathrm{p}<.01)$, regular words $(r=.37, p<.10)$, and irregular words $(r=-.42$, $p<.06)$. However, the other correlations involving silent reading time showed a pattern different from Experiment 1 . The correlations between reading time and reaction time to nonwords, regular words, and irregular words did not approach significance. The difference score formed by subtracting the regular-word reaction time from the irregular-word reaction time did not correlate significantly with silent reading time $(r=-.02)$ or WRAT score $(r=-.15)$.

\section{EXPERIMENT 3}

Although Experiments 1 and 2 appear to have demonstrated that phonological recoding does occur in word recognition, the tasks employed are not immune from criticism by those theorists who support the direct visual access position. As previously mentioned, the naming task is subject to the criticism that it is not an approximate analog to the word-recognition process that occurs in actual silent reading since the task does not require lexical access, but instead demands overt pronunciation.

It is also possible that the lexical decision task overestimates the extent to which phonological recoding mediates word recognition in actual reading. Suppose a dual-coding model with a visual access process that is much faster than phonological access is the appropriate model for word recognition in silent reading. Word 
recognition would typically occur via visual access. However, in a lexical decision task, a subject might adopt a conservative criterion and respond only after both types of access have occurred (i.e., he checks to make sure the letter string "sounds" like a word as well as "looks" like a word). Meyer et al. (1974) discuss how such a dual-coding conservative-criterion notion would make reaction time dependent on whichever of the two processes is slower. Thus, the argument that would be made by the visual access theorists such as Smith (1971) is that reaction times in lexical decision tasks are partially a function of processes occurring subsequent to word recognition. For example, Theios and Muise (1977) suggest that the reason lexical decision times always exceed naming times is that, "the information an observer needs in order to make a positive lexical decision is available only after he has read the word and understands its semantic meaning" (p. 314).

Fortunately, an experimental technique exists that allows the above conjecture to be tested. Specifically, the technique allows the experimenter to control the duration of the subject's reaction time. Thus it is possible to make subjects respond in the lexical decision task with a speed that would make processing dependent upon the fastest code (or, at the very least, prevent any sort of "rechecking" process like that described above). The response time deadline technique involves defining a criterion time for the subject prior to a block of trials. The subject attempts to emit his response prior to the deadline and is given feedback as to his success on a trial-by-trial basis. After a little practice with the procedure, the subject will consistently respond slightly faster than the criterion time. His error rate will also vary reliably with the stringency of the criterion. It then becomes possible, via the deadline technique, to equate reaction times over several experimental conditions and use the error rate as an index of processing difficulty. The feasibility of this experimental logic was shown in an experiment that addressed the question of whether stimulus probability had an effect on performance in a naming task (Stanovich \& Pachella, 1976).

The response-deadline technique has been used in experiments involving both verbal (Stanovich, Pachella, \& Smith, 1977) and manual responses (Pachella \& Pew, 1968) and has been applied to a variety of problems in cognitive psychology (see Pachella, Smith, \& Stanovich, 1978; Stanovich et al., 1977). In Experiment 3 the deadline technique is applied to the lexical decision paradigm in order to force the subject to emit a response faster than usual, thus insuring that his performance will not reflect dependence on either the slowest code or on "rechecking" processes subsequent to initial lexical access. The responsedeadline technique will lead to similar reaction times across the two conditions and any difference in word type will be seen in the error rates.

\section{Method}

Subjects. The subjects were 16 undergraduate college students who were recruited through an introductory psychology subject pool. None had participated in Experiments 1 or 2.

Stimuli and Apparatus. The stimuli and apparatus were the same as in Experiment 2.

Procedure. Subjects were first given practice with the response-deadline procedure. They were told that they would be seeing strings of letters and that they were to push the left button if the string was a word, otherwise they were to push the right button. They were informed of the deadline and told to look at the lower right part of the screen after every trial for feedback as to the speed of their response. The feedback was either the word "fast" or the word "slow," depending upon whether the subject had emitted the response before or after the response time deadline. Practice trials were run in blocks of 10 , using the words feel, step, and hint, and the nonwords wilp and folr. The experimenter varied the deadline in the range $300-500 \mathrm{msec}$ and practice continued until a deadline was found that the subject could consistently beat while producing approximately $20 \%$ errors (about seven to eight blocks of practice trials were usually necessary in order to meet these criteria). Then, working under this deadline, the subject completed a block of 150 trials in which the stimuli of Experiment 2 were displayed.

\section{Results and Discussion}

The mean reaction time to the regular words was $336 \mathrm{msec}(\mathrm{SE}=15 \mathrm{msec})$ and the mean reaction time to the irregular words was $338 \mathrm{msec}(\mathrm{SE}=15 \mathrm{msec}$ ). The small difference in reaction times did not approach significance $[t(15)=.42]$. It appears that the responsedeadline technique was successful in producing reaction times that were markedly faster (by $297 \mathrm{msec}$ ) than those obtained in the standard lexical decision situation of Experiment 2. The method also led to equivalent reaction times in the two experimental conditions. Thus, any processing difference between regular and irregular words would have to be reflected in the respective error rates. The mean percentage correct on regular-word trials was $84.0 \%$ and the mean percentage correct on irregular-word trials was $82.9 \%$, a difference that was not statistically significant $[\mathrm{t}(15)=.63]$. A reanalysis of the data using the standard arc-sine transformation for proportions yielded similar results $[\mathrm{t}(15)=1.17]$.

The response-deadline procedure of Experiment 3 was employed in order to reduce the possibility that operations subsequent to lexical access (e.g., phonological "rechecking") would contribute to performance. The lack of an effect on either the reaction times or the error rates in this experiment is supportive of the notion that regularity affects stages of processing subsequent to lexical access. However, interpretation of this information as supporting a direct visual access model (or a dual-coding model with visual access dominant) requires acceptance of the null hypothesis, a somewhat undesirable state of affairs. Experiment 4 will therefore address the issue with a different, but converging, experimental design. 


\section{EXPERIMENT 4}

Increasingly, researchers have turned to Stemberg's (1969) additive factors method when questions about the locus of an experimental effect have arisen. Interest has focused on whether various "cognitive" variables such as stimulus probability (Miller \& Pachella, 1973; Stanovich \& Pachella, 1977) and semantic context (Meyer, Schvaneveldt, \& Ruddy, 1975) have effects at the encoding stage of processing. The encoding stage, where a visual stimulus is turned into some abstract internal code, occurs early in the processing sequence and is affected by variables having to do with the quality of the stimulus display. Thus, Meyer et al. (1975) argued for an encoding locus of the semantic context effect in lexical decision tasks on the basis of a Stimulus Quality by Context interaction. Sanford, Garrod, and Boyle (1977) used a similar experimental logic in their investigations into a possible encoding locus for the conjoint frequency effect in semantic verification. Thus, the additive factors logic provides a converging operation as regards the question of the locus of the regularity effect observed in Experiments 1 and 2 . If the direct visual access view that phonological recoding occurs only after lexical access is correct, then stimulus quality should not interact with the regularity manipulation, since visual quality has its effects at an early encoding stage of processing. This prediction is tested in Experiment 4, where the regularity effect in a naming task is examined under two levels of stimulus quality.

\section{Method}

Subjects. The subjects were 16 undergraduate volunteers who were recruited through an introductory psychology subject pool for participation in the study. None had participated in Experiments 1, 2, or 3.

Stimuli and Apparatus. The stimuli and apparatus were the same as in Experiment 1 except that two levels (normal and degraded) of stimulus quality were employed. Degradation was produced by covering the entire face of the display with a sheet of acetate. The sheet reduced the intensity of the stimulus by 1.5 log units, thus reducing the contrast between stimulus and background.

Procedure. Subjects completed two blocks of 100 trials in which they named the stimulus words. One block was completed under the normal stimulus condition and one block was completed under the degraded stimulus condition. The order of stimulus conditions was counterbalanced across subjects.

\section{Results}

In the normal stimulus condition, the mean reaction time for regular words was $658 \mathrm{msec}(\mathrm{SE}=26)$ and the mean reaction time for irregular words was $693 \mathrm{msec}$ $(\mathrm{SE}=34)$. In the degraded stimulus condition, the mean reaction time for regular words was $833 \mathrm{msec}$ $(\mathrm{SE}=27)$ and the mean reaction time for irregular words was $832 \mathrm{msec}(\mathrm{SE}=24)$. An analysis of variance was carried out on the data treating regularity and stimulus quality as within-subjects factors and order of stimulus conditions as a between-subjects factor. The effect of stimulus quality was significant at the .001 level $[F(1,14)=25.00]$. The effect of order of stimulus conditions was not significant and this variable did not enter into any significant interactions. The effect of regularity was significant $[F(1,14)=4.69, p<.05]$, and the Regularity by Stimulus Quality interaction was not significant $[\mathrm{F}(1,14)=3.01, .10<\mathrm{p}<.15]$. A separate analysis using only the data from Block 1 (where the subject saw the stimuli for the first time) and treating stimulus quality as a between-subjects factor yielded similar results, indicating that the effects described above are not due to the subjects' responding twice to the same stimuli.

\section{GENERAL DISCUSSION}

Experiments 1 and 2 established the existence of a small, but reliable, regularity effect in word recognition. It is interesting that the naming and the lexical decision tasks produced regularity effects of similar magnitude, given that these two tasks have not yielded converging results in other word-recognition experiments. Thus, the effect seems general enough to be revealed in tasks that differ greatly in their basic processing requirements.

Experiments 3 and 4 were designed to investigate the locus of the regularity effect in the processing sequence. The results from both experiments suggest that the phonological recoding implied by the existence of the regularity effect takes place subsequent to lexical access. No regularity effect was apparent in the reaction times or error rates produced in Experiment 3, where the subject was responding faster than usual due to a response deadline. The deadline procedure was used in order to preclude the use of a conservative strategy whereby the subject waits for both a visual and a slower phonological access to the lexicon to occur before making a decision. The fact that the regularity effect disappeared in Experiment 3 is consistent with both a model in which phonological recoding processes occur entirely after lexical access and a model in which phonological access to the lexicon occurs in parallel with visual access, but at a slower rate. The main result of Experiment 4, that the regularity effect was not dependent on the visual quality of the stimulus display, suggests that the effect has its locus after the encoding stage where a stimulus makes contact with a memory representation.

Taken as a whole, the results of the experiments reported above do not give much support to theories of word recognition in which phonological mediation plays a major role. The regularity effect, although real, appears to be small in magnitude. Furthermore, the phonological coding operation that presumably accounts for the regularity effect appears either to take place after lexical access or in parallel with, but slower than, access based on a visual representation. 


\section{REFERENCES}

Baron, J., \& Strawson, C. Use of orthographic and word-specific knowledge in reading words aloud. Journal of Experimental Psychology: Human Perception and Performance, 1976, 2, 386-393.

CosKY, M. J. The role of letter recognition in word recognition. Memory \& Cognition, 1976, 4, 207-214

Frederiksen, J. R., \& KRolL, J. F. Spelling and sound: Approaches to the internal lexicon. Journal of Experimental Psychology: Human Perception and Performance, 1976, 2. 361-379.

Gough, P. B., \& Cosky, M. J. One second of reading again. In N. J. Castellan, D. B. Pisoni, \& G. R. Potts (Eds.), Cognitive theory (Vol. 2). Hillsdale, N.J: Lawrence Erlbaum, 1977.

Green, D. W., \& Shallice, T. Direct visual access in reading for meaning. Memory \& Cognition, 1976, 4, 753-758.

HuEY, E. B. The psychology and pedagogy of reading. Cambridge, Mass: M.I.T. Press, 1968. (Originally published, 1908.)

KEPPEL, G. Discussion of Wike and Church's comments. Journal of Verbal Learning and Verbal Behavior, 1976, 15, 263-266.

Kleiman, G. M. Speech recoding in reading. Journal of Verbal Learning and Verbal Behavior, 1975, 14, 323-339.

Kučera, H., \& Francis, W. N. Computational analysis of present-day American English. Providence, R.I: Brown University Press, 1967.

MeYer, D. E., Schyaneveldt, R. W., \& Ruddy, M. G. Functions of graphemic and phonemic codes in visual word recognition. Memory \& Cognition, 1974, 2, 309-321.

Meyer, D. E., Schvaneveldt, R. W., \& Ruddy, M. G. Contextual effects on word recognition. In P. M. A. Rabbitt \& S. Dornic (Eds.), Attention and performance V. New York: Academic Press, 1975

Miller, J. O., \& Pachella, R. G. Locus of the stimulus probability effect. Journal of Experimental Psychology, 1973, 101. 227-231.

Pachella, R. G., \& Pew, R. W. Speed-accuracy tradeoff in reaction time: Effect of discrete criterion times. Journal of Experimental Psychology, 1968, 76, 19-24.

Pachella, R. G., Smith, J. E. K., \& Stanovich, K. E. Qualitative error analysis and speeded classification. In J. Castellan \& F. Restle (Eds.), Cognitive theory (Vol. 3). Hillsdale, N.J: Lawrence Erlbaum, 1978.

Richardson, J. T. E. The effects of stimulus attributes upon latency on word recognition. British Journal of Psychology, 1976, 67, 315-325.
Rubenstein, H., Lewis, S. S., \& Rubenstein, M. A. Evidence for phonemic recoding in visual word recognition. Journal of Verbal Learning and Verbal Behavior, 1971, 10, 645-657.

SAFfran. E. M., \& Marin, O. S. M. Reading without phonology: Evidence from aphasia. Quarterly Journal of Experimental Psychology, :977, 29. 515-525.

Sanford, A. J., Garrod, S., \& Boyle, J. M. An independence of mechanism in the origins of reading and classification. related semantic distance effects. Memory \& Cognition, 1977, 5. $214-220$.

Scarborough, D. L., Cortese, C., \& Scarborough, H. S. Frequency and repetition effects in lexical memory. Journal of Experimental Psychology: Human Perception and Performance, $1977,3,1-17$

Shulman, H. G., \& Davison, T. C. B. Control properties of semantic coding in a lexical decision task. Journal of Verbal Learning and Verbal Behavior, 1977, 16, 91-98.

Sмiтн, F. Understanding reading. New York: Holt, Rinehart \& Winston, 1971.

Stanovich, K. E., \& Pachella, R. G. The effect of stimulus probability on the speed and accuracy of naming alphanumeric stimuli. Bulletin of the Psychonomic Society, 1976, 8, 281-284.

Stanovich, K. E., \& Pachella, R. G. Encoding, stimulusresponse compatibility, and stages of processing. Journal of Experimental Psychology: Human Perception and Performance. 1977, 3, 411-421.

Stanovich, K. E., Pachella, R. G., \& Smith, J. E. K. An analysis of confusion errors in naming letters under speed stress. Perception \& Psychophysics, 1977, 21, 545-552.

STERnBERG, S. The discovery of processing stages: Extensions of Donders' method. In W. G. Koster (Ed.), Attention and performance II. Amsterdam: North-Holland, 1969.

Theios, J., \& Muise, J. G. The word identification process in reading. In N. J. Castellan, D. B. Pisoni, \& G. R. Potts (Eds.), Cognitive theory (Vol. 2). Hillsdale, N.J: Lawrence Erlbaum, 1977.

VENEZKY, R. L. The structure of English orthography. The Hague: Mouton, 1970.

Wike, E., \& Church, J. Comments on Clark's "The languageas-a-fixed-effect fallacy." Journal of Verbal Learning and Verbal Behavior, 1976, 15, 249-255.

(Received for publication December 22, 1977; accepted May 18, 1978.) 